\title{
DESIGN AND ANALYSIS OF TUBULAR CHASSIS OF GO-KART
}

\author{
Prashant Thakare ${ }^{1}$, Rishikesh Mishra ${ }^{2}$, Kartik Kannav $^{3}$, Nikunj Vitalkar ${ }^{4}$, Shreyas Patil ${ }^{5}$, \\ Snehal Malviya ${ }^{6}$ \\ ${ }^{1}$ UG Students, Department of Mechanical Engineering, Prof. Ram Meghe institute of Technology and Research, \\ Badnera-Amravati, Maharashtra, India \\ ${ }^{2} U G$ Students, Department of Mechanical Engineering, Prof. Ram Meghe institute of Technology and Research, \\ Badnera-Amravati, Maharashtra, India \\ ${ }^{3}$ UG Students, Department of Mechanical Engineering, Prof. Ram Meghe institute of Technology and Research, \\ Badnera-Amravati, Maharashtra, India \\ ${ }^{4} U G$ Students, Department of Mechanical Engineering, Prof. Ram Meghe institute of Technology and Research, \\ Badnera-Amravati, Maharashtra, India \\ ${ }^{5}$ UG Students, Department of Mechanical Engineering, Prof. Ram Meghe institute of Technology and Research, \\ Badnera - Amravati, Maharashtra, India \\ ${ }^{6}$ UG Students, Department of Mechanical Engineering, Prof. Ram Meghe institute of Technology and Research, \\ Badnera - Amravati, Maharashtra, India
}

\begin{abstract}
Chassis is the basic and most important component or sub system which assimilates as a structure for various vehicles. It serves in giving the structural safety and also for embedding various systems like steering, powertrain, suspension and braking system on to it, thus having a dual purpose. This makes the chassis the robust and most cautious component to design, especially in race cars like go- kart. Keeping in mind the weight aspect of vehicle and its effect on performance of kart and considering the maximum safety the kart was designed. To satisfy all these criteria it is very crucial to keep in mind various parameters like material selection, cross-section of tubes, forces developed during impacts that might occur on track. Through this study, we aimed to design and analyze the chassis so as to achieve high strength to weight ratio. With the help CAD modeling software CATIA V5 R21 and Ansys workbench 14.5 the model was designed, analyze and optimized to serve the purpose. Material selection was tough task and hence ample market survey was done. This process was done in designing and fabricating the Go-Kart for National kart Racing Championship (NKRC) and it proved to be efficient.
\end{abstract}

Keywords: Chassis, Performance, CATIA V5 R21, Ansys 14.5, Weight to strength, NKRC.

\section{INTRODUCTION}

Chassis is the structure which consists of the various cross section tubes and tubing thickness to support the various vehicle components and also to protect the driver. The design discussed in this paper is for the vehicle which is driven by Discover $125 \mathrm{cc}$ engine. Since it is a kart used to run on the smooth track the speed is most important factor and to back this up weight of vehicle and thus reducing the weight of the chassis keeping in mind the vital factor i.e. strength to weight ratio. To optimize the design, the use of 3D modeling software and analysis software Ansys is used at greater extent. The following paper discusses the methodology and calculations for best optimizing the design of kart. It covers the design constraints given by the NKRC rulebook, the material selection, initial design, structural analysis and design modifications. And at last it will contain the final results which are desired to serve in real practice. To have the good acceleration it is recommended to have low weight as much as possible and to do so some compromises are needed to be done.

\section{MATERIAL SELECTION PARAMETERS}

For the selection of material for chassis, we have done some detailed study of properties of material regarding strength and cost and after that we found two materials AISI 1018 and AISI 1020 which are having similar properties. But we have decided to use AISI 1018 over AISI 1020, because of its higher yield strength and high strength to weight ratio. The material AISI-1018 is used in the chassis design because of its good weld ability, relatively soft and strengthens as well as good manufacturability. A good strength material is important in a roll cage because the roll cage needs to absorb as much energy as possible to prevent the roll cage material from fracturing at the time of high impact. AISI- 1018 has chosen for the chassis.

Table 1: Material Properties

\begin{tabular}{|l|l|}
\hline Material AISI 1018 \\
\hline Ultimate Strength & $420 \mathrm{MPa}$ \\
\hline Yield Strength & $310 \mathrm{MPa}$ \\
\hline Density & $7870 \mathrm{~kg} / \mathrm{m}^{3}$ \\
\hline Strength to Weight Ratio & $60 \mathrm{KN}-\mathrm{m} / \mathrm{kg}$ \\
\hline Elongation & $15 \%$ \\
\hline
\end{tabular}


The chemical Composition of material is:

$\begin{array}{ll}\text { Carbon } & \mathrm{C}=0.18 \% \\ \text { Manganese } & \mathrm{Mn}=0.73 \% \\ \text { Silicon } & \mathrm{Si}=0.18 \% \\ \text { Sulphur } & \mathrm{S}=0.017 \% \\ \text { Iron } & \mathrm{Fe}=98.81 \%\end{array}$

\section{CAD MODEL}

The entire Space frame was modeled in CATIA V5 R21 software.

The following are the considerations for the design:

- Driver Ergonomics: The emphasis of the design is on driver comfort

- Nodal Geometry: To increase the load transfer path.

- Mounting points for the integration of Suspension, Transmission, Steering and Brakes.

\section{Variable Thickness Tubing:}

- Primary Tube

1inch $\times 2 \mathrm{~mm}$ (light yellow)

- Secondary Tube

1 inch $\times 1.65 \mathrm{~mm}($ green $)$

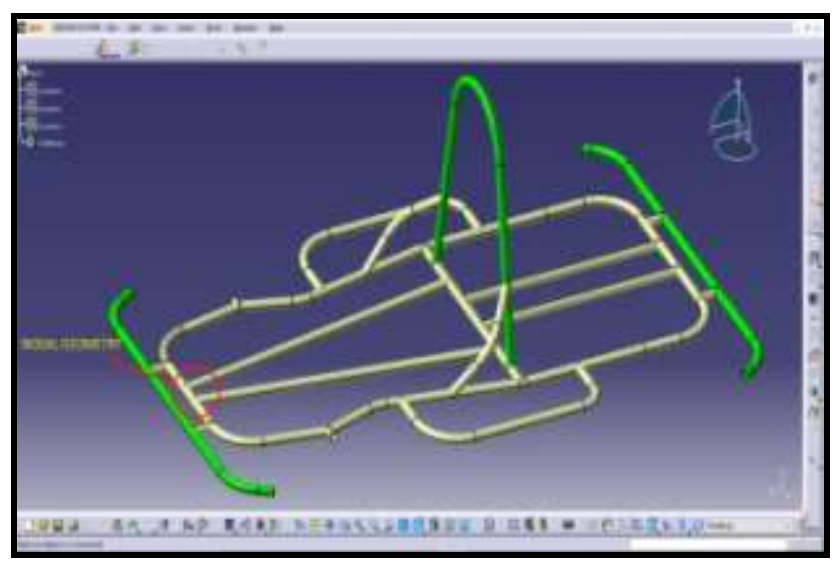

Fig- 1: CAD model of Chassis

\section{FINITE ELEMENT ANALYSIS}

Aside from exceeding the minimum material requirement set by the discussion in team members. Structural integrity of the frame was verified by comparing the analysis result with the standard values of the material. Analysis was conducted by use of finite element analysis FEA on ANSYS software. To conduct finite element analysis of the chassis an existing design of chassis is uploaded from the computer stresses are calculated by simulating three different induced load cases. The load cases simulated were frontal impact, side impact, and rear impact. The test results showed that the deflection was within the permitted limit.

The chassis is analyzed for various impacting conditions like front impact, rear impact and side impact with main focus on the driver's safety and after some iteration in design the best suitable design optimization is opted.

\subsection{Meshing}

Auto meshing has been done in ANSYS 14.5 software. Following data has been found after meshing of chassis -

Table 2: Meshing Data

\begin{tabular}{|l|l|}
\hline No. of Nodes & 77632 \\
\hline No. of elements & 154464 \\
\hline
\end{tabular}

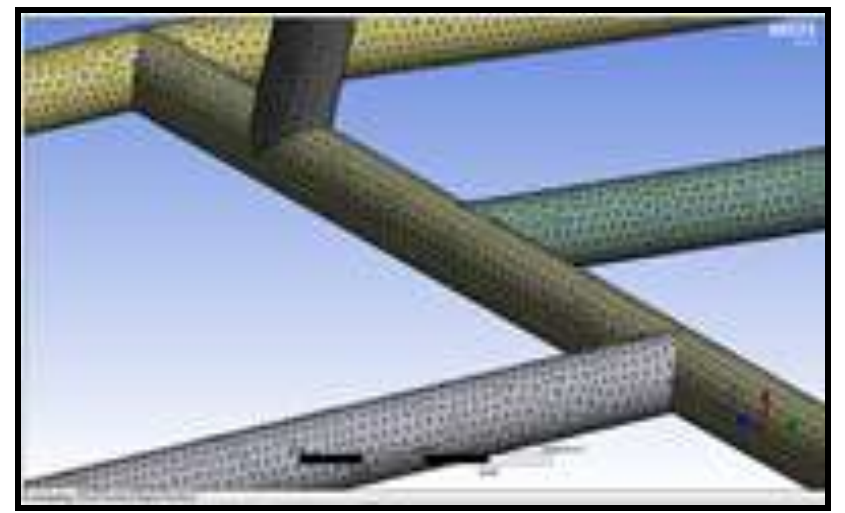

Fig- 2: Auto meshing in ANSYS 14.5

\section{IMPACT ANALYSIS}

The Impact forces were calculated using Newton's second law which states that the net force acting on a body is equal to the product of mass and acceleration of the body.

Force $=$ mass $\times$ acceleration

Force $=$ rate of change of momentum

Impulse $=$ Force $\times$ time $=$ change in momentum $=$ mass $\times$ change in velocity

\subsection{Front Impact}

For the front impact, engine and driver load was given at respective points. The kingpin mounting points and rear wheels position kept fixed. Front impact was calculated for an optimum speed of $60 \mathrm{kmph}$. From impulse momentum equation, $4 \mathrm{~g}$ force has been calculated. The loads were applied only at front end of the chassis because application of forces at one end, while constraining the other, results in a more conservative approach of analysis. Time of impact considered is 0.2 seconds as per industrial standards.

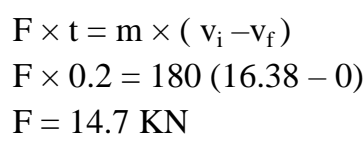

- $\quad$ Force applied on : Front Bumper

- $\quad$ Fixed Positins : Wheel mounting positions 


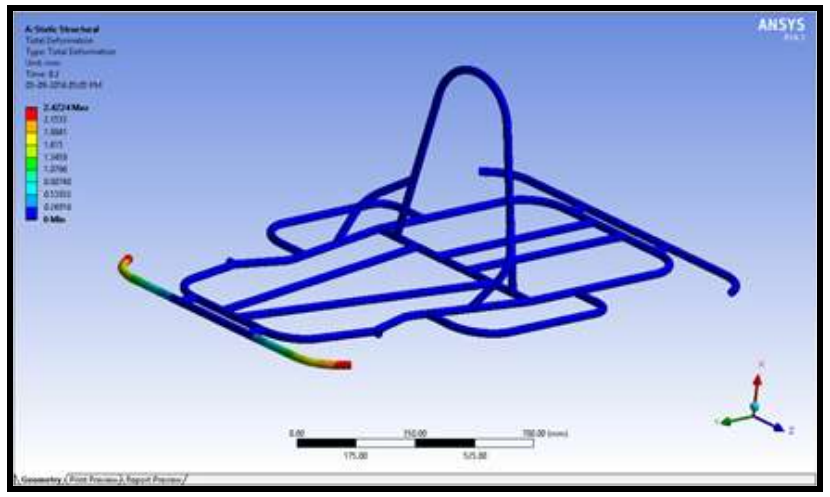

Fig- 3: Deformation

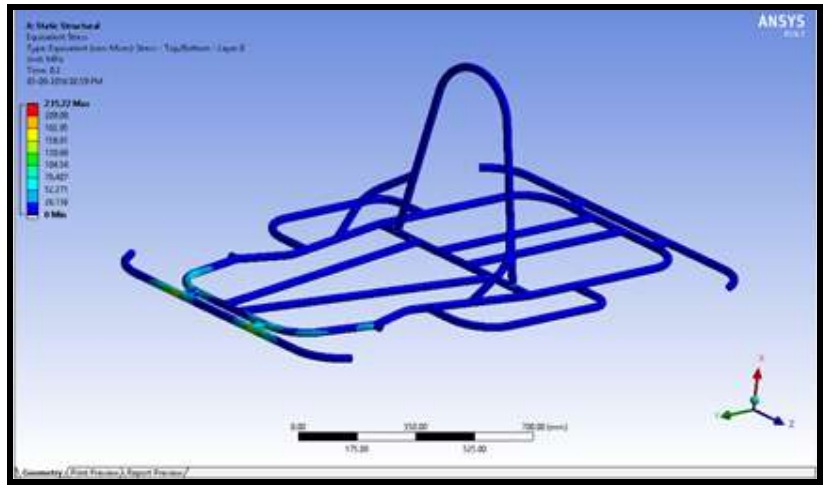

Fig - 4: Equivalent Stress

Table 3: Frontal Impact

\begin{tabular}{|l|l|}
\hline Deformation & $2.422 \mathrm{~mm}$ \\
\hline Max. Stress & $235.22 \mathrm{MPa}$ \\
\hline Factor of Safety & 1.3 \\
\hline
\end{tabular}

\section{Modifications:}

Triangulation was done at the front side so that the force is travelled in the body and is minimized.

\subsection{Rear Impact}

Considering the worst case collision for rear impact, force was calculated as similar to front impact for speed of 60 $\mathrm{kmph}$. The value of $3.5 \mathrm{~g}$ force has been calculated. Load was applied at rear end of the chassis while constraining front end and king pin mounting points. Time of impact considered is 0.2 seconds as per industrial standards.

$$
\begin{aligned}
& \mathrm{F} \times \mathrm{t}=\mathrm{m} \times\left(\mathrm{v}_{\mathrm{i}}-\mathrm{v}_{\mathrm{f}}\right) \\
& \mathrm{F} \times 0.2=180(16.38-0) \\
& \mathrm{F}=14.7 \mathrm{KN}
\end{aligned}
$$

\section{- Force applied on : Rear Bumper}

- Fixed Positins : Wheel mounting positions

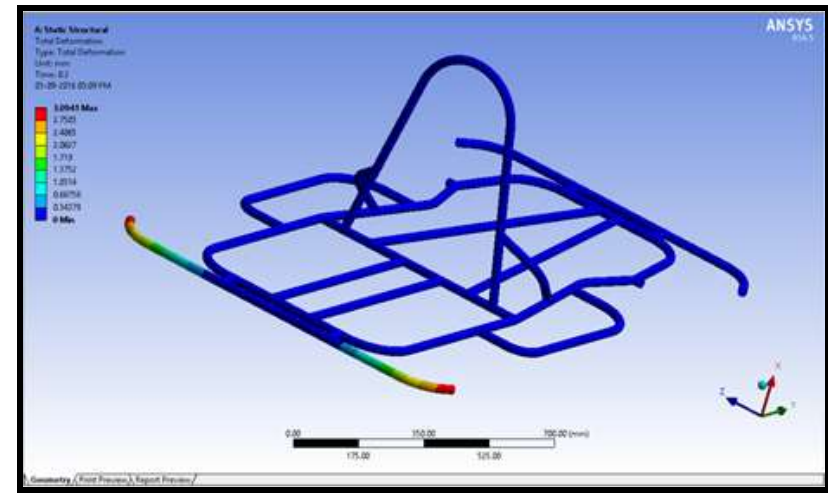

Fig- 5: Deformation

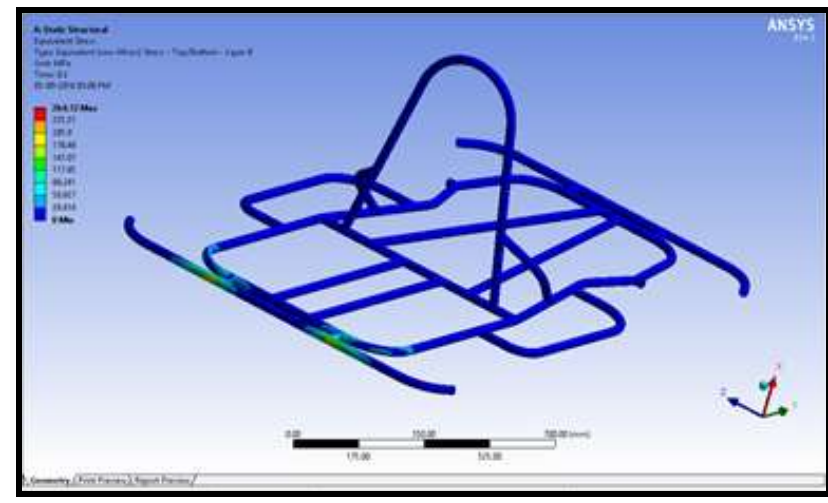

Fig- 6: Equivalent Stress

Table 4: Rear impact

\begin{tabular}{|l|l|}
\hline Deformation & $3.09 \mathrm{~mm}$ \\
\hline Max. Stress & $264.72 \mathrm{MPa}$ \\
\hline Factor of Safety & 1.17 \\
\hline
\end{tabular}

\section{Modification:}

The distance between the two straight members at rear was modified several times to check where the suitable position should be.

\subsection{Side Impact}

The most probable condition of an impact from the side would be with the vehicle already in motion. So it was assumed that neither the vehicle would be a fixed object. For the side impact the velocity of vehicle is taken $30 \mathrm{kmph}$ and time of impact considered is 0.2 seconds as per industrial standards. Impact force was applied by constraining left side of chassis and applying load equivalent to $3 \mathrm{~g}$ force on the right side.

$$
\begin{aligned}
& \mathrm{F} \times \mathrm{t}=\mathrm{m} \times\left(\mathrm{v}_{\mathrm{i}}-\mathrm{v}_{\mathrm{f}}\right) \\
& \mathrm{F} \times 0.2=180(8.19-0) \\
& \mathrm{F}=7.35 \mathrm{KN}
\end{aligned}
$$

- $\quad$ Force applied on : Side Bumper

- Fixed Positins : Wheel mounting positions 


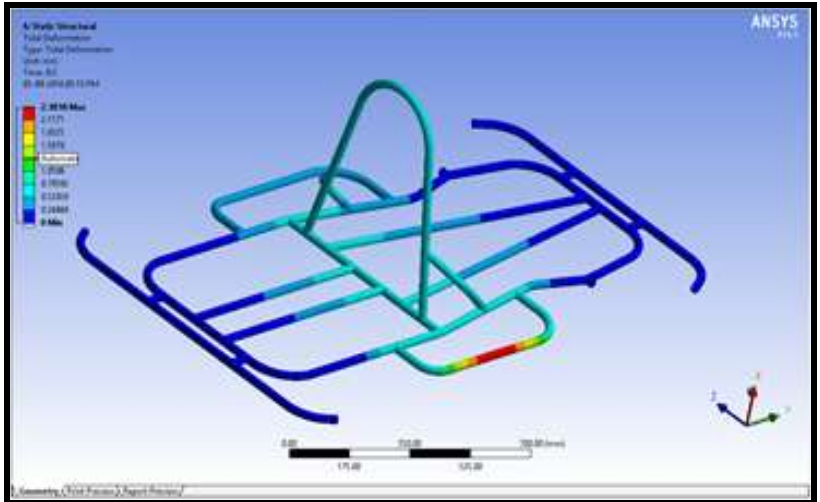

Fig- 7: Deformation

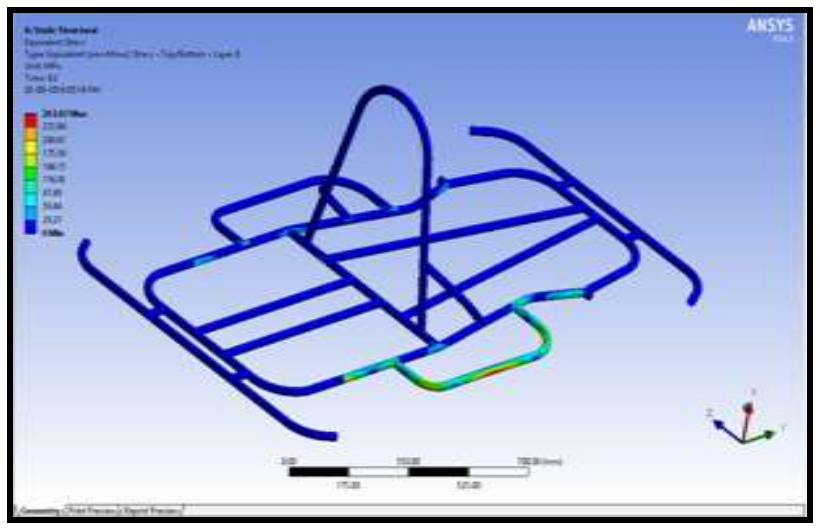

Fig- 8: Equivalent Stress

Table 5: Side Impact

\begin{tabular}{|l|l|}
\hline Deformation & $2.38 \mathrm{~mm}$ \\
\hline Max. Stress & $263.07 \mathrm{MPa}$ \\
\hline Factor of Safety & 1.17 \\
\hline
\end{tabular}

\section{Modification:}

The distance of the side bumper end from the fire wall was taken near so the stress developed should travel to the node of firewall.

\subsection{Torsion}

The chassis should be stiff enough to sustain dynamic suspension loads. When the vehicle is negotiating the bump there might be a case of alternating bumps on left and right wheels. The couple is applied on the chassis on the alternate wheel mounts and the analysis was done to see whether it sustains or not.

Standard force of $3 \mathrm{~g}$ was applied on the wheel mounts.

- $\quad$ Force applied on : Diagonally opposite wheel mounts

- Fixed Positins : Opposite Wheel mounting positions

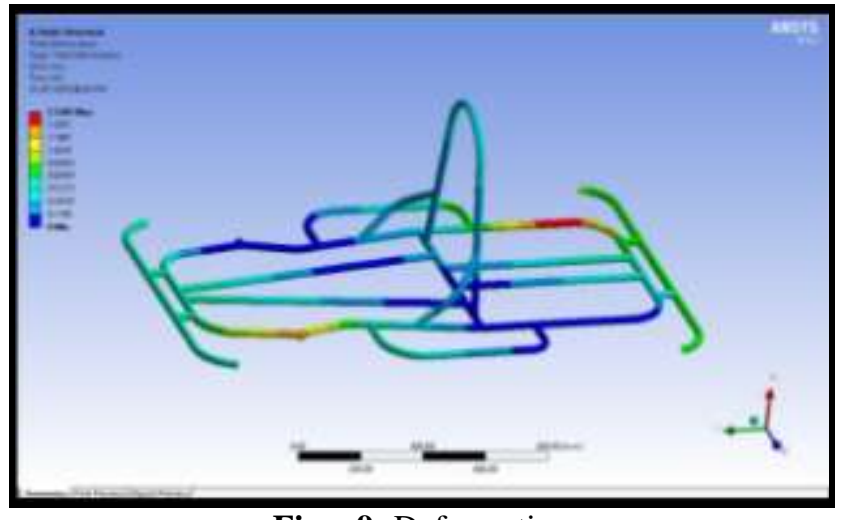

Fig - 9: Deformation

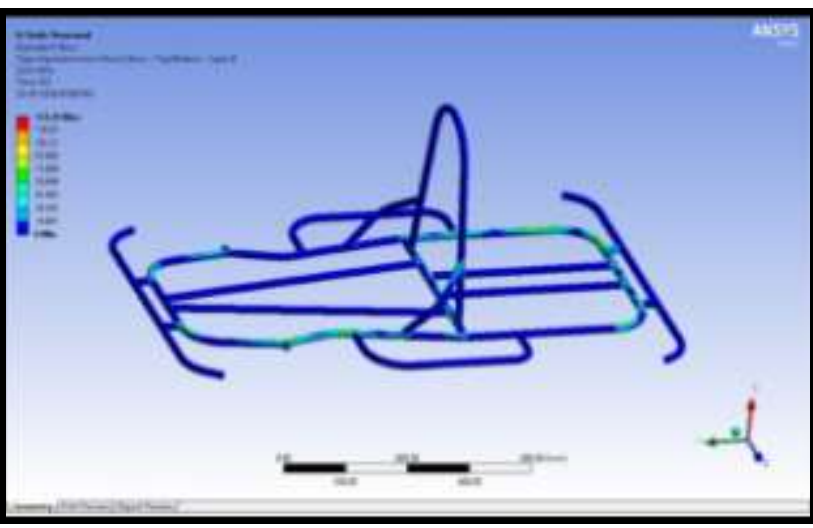

Fig - 10: Equivalent Stress

Table 6: Torsion

\begin{tabular}{|l|l|}
\hline Deformation & $1.51 \mathrm{~mm}$ \\
\hline Max. Stress & $131.41 \mathrm{MPa}$ \\
\hline Factor of Safety & 2.35 \\
\hline
\end{tabular}

\section{CONCLUSION}

After performing the Front impact, side impact and rear impact analyses and making the necessary changes, the following design was finalized.

- The above designed chassis is much stiffer and stronger than the previously designed one. The chassis members were optimized by changing dimensions of the pipes in required positions and after several iterations the design was finalized.

- The above calculations and analysis was done considering the extreme limits and then also the chassis showed sustainable results but in actual such harsh conditions won't occur so the stress and deformations will be less than those occurred during analysis.

- The analysis was done without considering the shock absorbing components so if they would have been considered the stresses developed would have much less.

\section{ACKNOWLEDGEMENT}

We are very much grateful to Team Acrux and Team Triumph Racers who supported and shared the required resources. 


\section{REFERENCES}

[1]. Thomas D. Gillespie. Fundamentals of Vehicle Dynamics Society of Automotive Engineers, Inc.

[2]. Racing kart plans www.kartbuilding.net

[3]. Team Acrux- Go-kart Racing Team, Final design Report, Submitted at National Kart Racing ChampionshipSeason 3, September 2016

[4]. Rulebook of NKRC 2016

\section{BIOGRAPHIES}

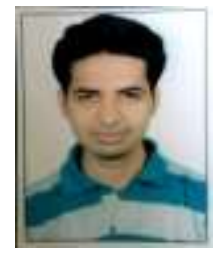

Prashant Thakare, Team Captain of Triumph Racers, Designing Head of Team Triumph Racers and Team Acrux

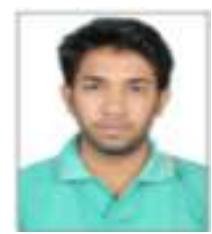

Rishikesh Mishra, Transmission head of Team Acrux

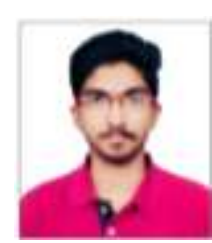

Kartik Kannay, Vice-Captain of Team Acrux, Analysis Head of Team Acrux

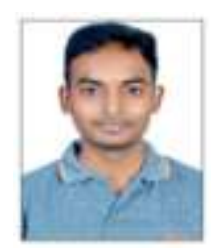

Kartik Kannav, Vice-Captain of Team Acrux, Analysis Head of Team Acrux

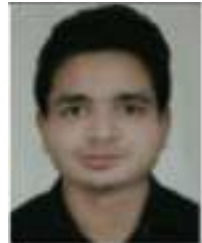

Shreyas Patil, Chassis Head of Team Acrux

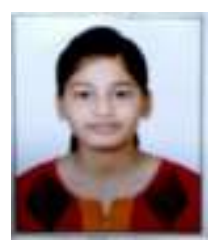

Senhal Malviya, Braking Head of Team Acrux 